University of Louisville

ThinkIR: The University of Louisville's Institutional Repository

Faculty Scholarship

8-2013

\title{
The combined effects of self-referent information processing and ruminative responses on adolescent depression.
}

Stephanie Winkeljohn Black

University of Louisville

Patrick Pössel

University of Louisville

Follow this and additional works at: https://ir.library.louisville.edu/faculty

Part of the Counseling Psychology Commons

Original Publication Information

Winkeljohn Black, Stephanie and Patrick Pössel. "The Combined Effects of Self-Referent Information Processing and Ruminative Responses on Adolescent Depression." 2013. Journal of Youth and Adolescence 42(8): 1145-1154.

This Article is brought to you for free and open access by ThinkIR: The University of Louisville's Institutional Repository. It has been accepted for inclusion in Faculty Scholarship by an authorized administrator of ThinkIR: The University of Louisville's Institutional Repository. For more information, please contact thinkir@louisville.edu. 


\begin{abstract}
Adolescents who develop depression have worse interpersonal and affective experiences and are more likely to develop substance problems and/or suicidal ideation compared to adolescents who do not develop depression. This study examined the combined effects of negative self-referent information processing and rumination (i.e., brooding and reflection) on adolescent depressive symptoms. It was hypothesized that the interaction of negative self-referent information processing and brooding would significantly predict depressive symptoms, while the interaction of negative self-referent information processing and reflection would not predict depressive symptoms. Adolescents $(n=92 ; 13-15$ years; $34.7 \%$ female) participated in a six-month longitudinal study. Self-report instruments measured depressive symptoms and rumination; a cognitive task measured information processing. Path modelling in Amos 19.0 analyzed the data. The interaction of negative information processing and brooding significantly predicted an increase in depressive symptoms six months later. The interaction of negative information processing and reflection did not significantly predict depression, however, the model not meet a priori standards to accept the null hypothesis. Results suggest clinicians working with adolescents at-risk for depression should consider focusing on the reduction of brooding and negative information processing to reduce long-term depressive symptoms.
\end{abstract}

Key words: information processing; rumination; brooding and reflection; adolescent depression 


\section{Introduction: The Combined Effects of Self-referent Information Processing and}

\section{Ruminative Responses on Adolescent Depression}

A meta-analysis of epidemiological studies on adolescent depression found a $5.7 \%$ rate

2006). Moreover, adolescents with depressive symptoms are more likely to have interpersonal problems and to develop major depression, suicidal ideation, anxiety, and/or substance abuse problems compared to adolescents without depressive symptoms (Marttunen, Haarsilta, AaltoSetälä, \& Pelkonen, 2003). Therefore, an examination of the risk factors associated with adolescent depression is critical to developing prevention and intervention methods for depression. Two important cognitive constructs related to depression and/or depressive symptoms are self-referent information processing and rumination.

Beck's cognitive theory (1976) asserts that an individual's information processing can be obscured by maladaptive schemata, which is associated with depression. Nolen-Hoeksema's response styles theory asserts that individuals who ruminate on a particular negative event can worsen or instigate a depressed mood (Nolen-Hoeksema \& Morrow, 1991). Both of these theories propose that cognitive styles and cognitive processes (i.e., rumination, information processing and schemata) are risk factors for depressive symptoms. Researchers have begun to explore these theoretical constructs together as they relate to depressive symptoms (Alloy et al., 2004; Ciesla \& Roberts, 2007; Pössel, 2011; Robinson \& Alloy, 2003). Studies have shown support for a moderation model wherein information processing and rumination interact to predict depressive symptoms (e.g., Ciesla \& Roberts, 2007; Robinson \& Alloy, 2003). Despite the evidence in support of this moderation model, it has not been tested in an adolescent sample. Thus, the current study examined information processing and rumination as related to 
1 the cognitive theory and response styles theory with an adolescent sample.

\section{Information Processing}

3

5

Information processing occurs when an individual receives information from the environment and then encodes, processes, or retrieves the information as a memory. Many cognitive models of depression posit that biases in information processing (e.g., interpreting negative information as self-referent, or interpreting ambiguous stimuli as negative) are the principle cause of the onset and maintenance of depression (for a review, see Jacobs et al., 2008). An important, related construct that predicts to depression is a person's self-schema (Beck, 1987). A person's self-schema is a stable, cognitive structure of thought patterns that influence how a person codes and interprets external stimuli in relation to him-/herself (Beck, 1964). Beck (1987) posits additionally, negative schemas relate to functions of negatively biased information processing. Specifically, negative schemas cause people to recall negative aspects of a memory more readily than positive aspects of a memory. People are also more likely to ignore information from the environment that is contrary to their self-schema (Beck, 1987), which implies a bias in encoding or processing information from the person's surroundings. Additionally, schemata are dormant until they are activated through emotional experiences. In other words, an individual's negative schema would not be activated, or used, until they experienced a negative affective experience (Miranda \& Persons, 1988), making emotion an important component in studying cognitive constructs.

\section{Negative Self-Referent Information Processing}

Studies have found that negative self-referent information processing biases arise when the participants endorse a negative self-schema (Derry \& Kuiper, 1981; Dykman, Abramson, Alloy, \& Hartlage, 1989; Kuiper \& Derry, 1982). Additionally, studies have shown that the processing 
1 of a self-schema (i.e., how easily an individual can encode and recall a particular memory) may

2 contribute to differences between depressed and non-depressed individuals.

$3 \quad$ Using an adjective-encoding task, Kuiper and Derry (1982) found that depressed

4 individuals' self-schema, compared to non-depressed individuals, operate less efficiently when

5 recalling self-referent information. These results have been replicated in other adult samples

6 (e.g., Dozois \& Dobson, 2001).

7 Similar investigations have been conducted with adolescent samples. Using a self-

8 referent encoding and recall task similar to Kuiper and Derry’s (1982), one study found a

9 positive association between depressive symptoms and the endorsement of negative self-referent

10 adjectives among psychiatric inpatient adolescents (Gençöz, Voelz, Gençöz, Petit, \& Joiner,

11 2001). However, the researchers did not find a predictive relationship between the self-referent

12 processing task and depressive symptoms. Prinstein, Cheah, and Guier (2005) found similar

13 results with $10^{\text {th }}$ grade adolescents when examining peer attributions and victimization.

14 However, the positive association between negative self-referent adjectives and depressive

15 symptoms was only predictive for adolescent males experiencing high levels of peer

16 victimization.

17 Summarized, the established relationship between negative self-referent information

18 processing and depression in adults has also been found to a limited extent in adolescents.

19 Depressed individuals tend to have more negative self-schemas and are therefore more inclined

20 to process negative, rather than neutral and/or positive, self-referent information compared to

21 non-depressed individuals (Dozois \& Dobson, 2001; Gençöz et al., 2001; Prinstein et al., 2005).

22 More specifically, the operations in information processing differ between depressed and non-

23 depressed individuals, where depressed individuals store, process, and retrieve information in a 
1 negatively biased way (Dozois \& Dobson, 2001; Dykman et al., 1989; Gençöz et al., 2001; Kerry

2 \& Duiper, 1982; Prinstein et al., 2005). These findings lend support to Beck's theory (1964,

3 1987) that negative self-referent information processing contributes to depression.

\section{$4 \quad$ Rumination}

5 Rumination is a cognitive style which involves repetitive thinking in reaction to stressful

6 events and focuses on the origins and symptoms of the stressful event and subsequent distress

7 (Nolen-Hoeksema, Wisco, \& Lyubomirsky, 2008). Hilt, McLaughlin, and Nolen-Hoeksema

8 (2010) found that adolescents $\left(6^{\text {th }}\right.$ through $8^{\text {th }}$ grade) who had a high tendency to ruminate were

9 more depressed seven months later compared to adolescents with a low tendency to ruminate. In

10 a two year longitudinal study with adolescents aged 11-15 years, Abela and Hankin (2011) found

11 that high-ruminating adolescents were more likely than their low-ruminating peers to have future

12 major depressive episodes, and that these future episodes were more likely to last longer. Abela

13 and Hankin (2011) also controlled for participants' current and past levels of depression, making

14 their results even more compelling.

15 Although rumination is usually seen as a negative construct, further examinations of

16 ruminative subtypes reveals that some ruminative thoughts are negative while others are

17 considered neutral or even positive. Researchers have classified rumination into brooding and

18 reflection (Treynor et al., 2003). Brooding, which involves moody and passive thinking about

19 one's actions or situation (e.g., thinking about how a situation could have gone differently), has

20 been found to be maladaptive and be caused by perceived low mastery (i.e., controllability of a

21 situation or environment; Treynor et al., 2003). Burwell and Shirk (2007) also found that

22 brooding predicted adolescent self-reports of depressive symptoms over time. 
1 more active problem solving and contemplation compared to brooding. While it has been shown

2 to have a positive association with depression concurrently, it may have no longitudinal

3 association to depressive symptoms or actually alleviate depressive symptoms over time

4 (Burwell \& Shirk, 2007; Treynor et al., 2003). This was supported in a study with early

5 adolescents, where participants were better-adjusted if they engaged in more reflective thinking

6 instead of brooding (Lopez, Driscoll, \& Kistner, 2009). Thus, brooding is more likely increase

7 depressive symptoms over time, while reflection will not. Thus, it is important to consider these

8 ruminative subtypes' influence on depression separately. ${ }^{1}$

\section{$9 \quad$ Negative Self-Referent Information Processing and Rumination}

It is well established that individuals who ruminate have negatively biased information

11 processing when encoding and retrieving memories. For example, the Cognitive Vulnerability

12 to Depression (CVD; Alloy \& Abramson, 1999) Project has been investigating the relationship

13 between self-referent information processing and ruminative response styles, based on Beck's

14 cognitive theory (1976), Abramson's hopelessness theory (Abramson, Metalsky, \& Alloy, 1989),

15 and Nolen-Hoeksema's response styles theory (Nolen-Hoeksema \& Morrow, 1991) in college

16 students. Robinson and Alloy (2003) analyzed CVD data and found that negative cognitive

17 processes (e.g., negative inferential styles and dysfunctional attitudes) are associated with

18 depressive episodes when combined with rumination, a negative cognitive style. Robinson and

19 Alloy (2003) confirmed their hypothesis that the interaction of negative cognitive styles and

\footnotetext{
${ }^{1}$ Currently, the depression-related subtype of rumination is interpreted as a depressive symptom, not as an independent construct such as brooding and reflection (Treynor et al., 2003). Thus, depression-related rumination will not be examined in the current study.
} 
1 processes predicted depressive episodes.

2 Ciesla and Roberts (2007) had similar findings when they investigated the effects of

3 interactive cognitive vulnerabilities to depression. Ciesla and Roberts (2007) tested whether the

4 interaction of rumination and dysfunctional attitudes or rumination and negative attributional

5 style(s) predicted changes in dysphoric mood after inducing sadness in their participants. The

6 researchers' moderation model had mixed support. When rumination was combined with

7 dysfunctional attitudes the model did predict significant changes in dysphoric mood, but not

8 when rumination was combined with attributional style. Due to this unexpected result, Ciesla

9 and Roberts (2007) recommend that further research needs to be conducted to better understand

10 what variations in negative cognitive styles or processes might amplify the effects of rumination

11 on dysphoric or depressed mood.

Hypotheses

13 The current study examined longitudinally the interaction of negative self-referent

14 information processing and ruminative response styles as a predictor of depressive symptoms in

15 adolescents. While there are studies demonstrating that negative self-referent information

16 processing and ruminative brooding independently relate to adolescent depressive symptoms, no

17 study has examined the combination of these constructs in an adolescent sample. This is critical,

18 as constructs contributing to adolescent depressive symptoms can upset adolescents'

19 interpersonal relationships and is associated with substance abuse (Marttunen et al., 2003).

20 We expected that the interaction of negative self-referent information processing and

21 ruminative brooding would significantly predict depressive symptoms in adolescents over a six-

22 month period. It was expected that this interaction will more strongly predict depressive

23 symptoms six months later compared to the main effects of either negative self-referent 
1 information processing or ruminative brooding. That is, we expected that high levels of

2 brooding combined with high levels of negative self-referent information processing would

3 result in a higher level of depressive symptoms later. Accordingly, we expected that low levels

4 of brooding combined with low levels of negative information processing would result in lower

5 levels of depression symptoms six months later. Moreover, we expected that the interaction of

6 negative self-reference information processing and ruminative reflection would not significantly

7 predict depressive symptoms in adolescents over a six-month period. That is, we expected that

8 because reflection is a neutral, rather than negative, ruminative style, it would not combine with

9 negative information processing to cause greater depressive symptoms.

\section{Method}

\section{Participants}

12 Adolescents from a larger sample of 302 were randomly selected and invited to

13 participate in laboratory-based measures. The original sample $(n=302)$ was initially recruited

14 by sending letters to principals at six schools inviting them to participate in the study. Two

15 principals declined, leaving four remaining schools. Parent-teacher conferences were held to

16 explain the nature of the study to the teachers, parents, and students. All classes invited from the

17 remaining four schools agreed to participate. All of the parents and students from these four

18 schools agreed to participate. It is worth noting that this high participation rate is common in

19 school systems in Germany, because the students take their classes with the same 30 classmates

20 all four years. Therefore, students are more motivated to participate in the same programs their

21 classmates do.

22 The interest of the current study is vulnerability to depression rather than testing

23 the effects of the scar hypothesis, which asserts that individuals who have experienced 
1 depression show a negative cognitive bias compared to never depressed individuals

2 (Pössel \& Knopf, 2008). As this suggests that already depressed participants could bias

3 the data, participants were screened during the collection of the original sample $(n=302)$

4 for depression using the 12-item Depression-Screening Questionnaire (DSQ; Wittchen \&

5 Perkonigg, 1997), ${ }^{2}$ which measures the presence of current or past Major Depression

6 based on the DSM-IV-TR (APA, 2000). Participants who scored a 10 or higher met the

7 clinical cut-off and were excluded from the analysis $(n=21)$. For ethical reasons, these

8 adolescents with elevated DSQ scores were offered treatment instead. Scores on the

9 DSQ were the only inclusion/exclusion criteria for participation in the study.

10 The finale sample $(n=100)$ for this study comprised of adolescents aged 13 to 15 years

11 old $(M=13.58 ; S D=0.56)$, who attended public $(n=3)$ or private $(n=1)$ schools in a rural area

12 of southwest Germany. All adolescents who were invited for this laboratory study accepted the

13 offer. All participants were German nationals and spoke German as their primary language.

14 Although data on social-economic status of the students are not available, a wide range of social

15 classes is likely to be represented because students from schools in economically diverse regions

16 of the area. However, eight sets of data were lost due to technical difficulties, resulting in a final

${ }^{2}$ Participants answered the DSQ items based on all past experiences on a 3-po2int Likert scale (no, sometimes, most days). If an adolescent rated at least five items as experienced "most days" in the same two weeks or more, it indicated that the participant was experiencing a pattern of symptoms similar to a diagnosis of major depression (consistent with the DSM-IV-TR). Although the DSQ was developed for adults, it has been used with adolescents (see Essau, Karpinski, Petermann, \& Conradt, 1998; Pössel, Seeman, Ahrens, \& Hautzinger, 2006). 
1 sample of 92 participants (54 males, 32 females). The Institutional Review Board at Eberhard-

2 Karls University approved this study (Pössel, Seeman, \& Hautzinger, 2008).

\section{Materials}

Rumination. Rumination was measured with the Ruminative Responses Scale (RRS)

5 from the Response Styles Questionnaire (RSQ; Nolen-Hoeksema, Parker, \& Larson, 1994) at

6 both time points. The RRS measures both Brooding (e.g., "think, 'Why do I always react this

7 way?") and Reflection (e.g., "analyze recent events to try to understand why you are

8 depressed"). Each of these two subscales is comprised of five items asking participants how

9 often they engage in certain behaviours or thoughts when depressed, measured on a 4-point

10 Likert scale $(1=$ almost never, 4 = almost always; Treynor et al., 2003). Although the RRS

11 was developed for adults (Nolen-Hoeksema et al., 1994) it has been used in adolescent

12 samples (e.g., Wilkinson \& Goodyer, 2006). For the current sample, internal consistency for

13 the overall measure was strong at both time points (Cronbach's alpha $=.95$ and .87 ,

14 respectively). While internal consistency for the Brooding subscale was slightly lower than

15 preferred at both Time 1 and Time 2 (Cronbach's alpha $=.66, .68$, respectively), other studies

16 found comparable internal consistencies ranging from .60 (Pössel, 2011) to .77 (Treynor et

17 al., 2003). Internal consistency for the Reflection subscale was acceptable at both Time 1

18 and Time 2 (Cronbach's alpha $=.80, .73$, respectively), which were also comparable to

19 internal consistencies in other studies (Cronbach's alpha ranging from .68 to .73, Pössel,

20 2011, Treynor et al., 2003).

22 measured participants' level of depressive symptoms during the last two weeks at Time 1 and

23 Time 2. The SBB-DES is a self-report an instrument developed for children and adolescents to 

$5 \quad$ (Cronbach's alpha $=.91)$.

measure the presence and severity of depressive symptoms (Döpfner \& Lehmkuhl, 2000). The SBB-DES has 26 items, each on a 4-point Likert scale. The summary score represents the mean of the items and has a possible range from 0 to 3, with higher scores indicating a greater severity or presence of depressive symptoms. Internal consistency of the current measure was strong

Participants with SBB-DES scores greater than or equal to 1.23 (10\% of the sample) at Time 1 were considered "clinically relevant" (total range $=0.0-2.12$; Döpfner, Götz-Dorten, \& Lehmkuhl, 2008). Participants who scored in the "clinically relevant" category were not excluded from analyses because their elevated scores represented depressive symptoms rather than Major Depression symptoms (as seen on the DSQ). The proportion of participants experiencing depressive symptoms at Time 1 demonstrates that the sample represented a wide range of symptoms as seen in the general population.

Mood induction check. Participants reported their levels of sadness, anger, anxiety and happiness on a visual analogue scale before and after undergoing a mood induction (VAS; Kelvin, Goodyer, Teasdale, \& Brechin, 1999) at both Time 1 and Time 2. Self-Referent Information Processing. The computerized version of the self-referent encoding task paradigm (SRET; Kelvin et al., 1999; Kuiper \& Derry, 1982) was used at both time points in conjunction with word lists developed by Maes et al. (1998), which comprised 50 negative German adjectives that were comparable on emotional valence, meaning and fluency. Fluency was determined in a pilot study to ensure that German adolescents often used the SRET task words in normal conversations.

Word lists with 50 negative adjectives (e.g., dismal, bleak, egoistic, dishonest) were distributed to the participants. Participants were instructed to indicate whether each negative 
1 adjective applied to them (i.e., whether the adjective was self-referent) by marking either a "yes"

2 or a "no" next to the word on their word sheet over a 30 -second period. Next, participants were

3 asked to recall (i.e., incidental free recall) as many of the "yes-rated" (self-referent) negative

4 adjectives as possible during a three-minute period.

5 As the study was longitudinal, participants were informed at the beginning of the SRET

6 task that their word recall ability would be tested, to keep recall testing consistent between the

7 first and second sessions. The number of recalled yes-rated (self-referent) negative adjectives

8 was divided by the total number of yes-rated (self-referent) negative adjectives to create a

9 proportion for each participant. The resulting proportions range from 0 to 1 and denote the

10 percentage of accurately recalled adjectives for negative adjective groups. A higher proportion

11 of negative adjectives represent a more negative self-schema, or more negative self-referent

12 information processing (Kuiper \& Derry, 1982).

\section{Procedure}

The questionnaires measuring rumination and depressive symptoms were distributed and

15 completed in classrooms during the school day, and the SRET was conducted in individual

16 computer sessions in a university laboratory. Individual sessions began with an explanation of

17 the study procedure and informed consent. As schema need to be activated by affective

18 experiences (Miranda \& Persons, 1988), participants underwent a dysphoric mood induction

19 (Kelvin et al., 1999) by listening to a 3-minute clip of Prokofiev's “Alexander Nevsky-Russia

20 under The Mongolian Yoke," a piece meant to evoke images of destruction and loss.

21 Participants were also prompted to think of an experience in their lives when they were sad.

22 After this mood induction, participants completed a VAS to determine whether the mood

23 induction was successful, and then completed the SRET. To ensure participants did not leave in 
1 a depressed mood, participants listened to a 3-minute clip of "Taschenrechner" by the German

2 band, Kraftwerk and were asked to think about positive experiences they have had. They were

3 then given the VAS again to ensure that they left the laboratory in a less negative and more

4 neutral mood. . Participants completed the individual sessions and RRS and SBB-DES

5 questionnaires at Time 1 and then six months later at Time 2.

\section{Data Analysis}

The hypothesized model was tested with the maximum likelihood method by calculating

8 a path model in AMOS 19.0. The effects of depressive symptoms at time 1 were controlled for

9 and the main effects of ruminative brooding and negative self-referent information processing

10 were explored in the model. Additionally, given that there is much support regarding gender

11 differences in depressive symptoms (e.g., Nolen-Hoeksema, 2001; Rutter, 2007), gender was

12 placed into the model as a covariate at Time 1 and Time 2 . The goodness of fit of the models to

13 the data was tested with $\chi^{2}$. However, as this measure is sensitive to the number of participants in

14 the study, other measures, such as $\chi^{2} / d f$, Comparative Fit Index (CFI; Bentler, 1990), root mean

15 squared of the residuals (RMSEA; Steiger \& Lind, 1980), and Akaike Information Criterion

16 (AIC; Akaike, 1974) were also used. To further examine any statistically significant interaction

17 effects, the path model's regression equation was used to construct a model-implied graph which

18 would chart the interacting constructs' (i.e., ruminative brooding and negative self-referent

19 information processing) effects on depressive symptoms at Time 2 separately (main effects) and

20 together (interaction effect).

21 Each of the above measures for goodness of fit has specific parameters that must be

22 considered. Statistically nonsignificant values of $\chi^{2}$ and values of $\chi^{2} / d f$ that are smaller than 2

23 (Kline, 2005; Ullman, 1996) indicate a good fit of the model to the data. A CFI value of 1.00 
1 demonstrates a perfect model fit to the data, a value of $\geq .95$ demonstrates good model fit, and

2 values of $\geq .90$ are considered acceptable (Hu \& Bentler, 1999). An RMSEA value of .00

3 demonstrates a perfect model fit to the data, and values of $<.05$ are considered a good model fit,

4 though values of $<.08$ are regarded as acceptable (Hu \& Bentler, 1999).

$5 \quad$ Significance level for the alternative hypotheses was set at $5 \%$, and for the null

6 hypothesis that the interaction of negative self-referent information processing and ruminative

7 reflection did not predict depression it was set at $20 \%$. This level for the null hypothesis is

8 considered conservative (Bortz \& Döring, 2002).

\section{Results}

Descriptive data and intercorrelations of the measures are reported in Table A.1. It is worth noting that depressive symptom and rumination scores at Time 1 were significantly correlated with each other. However, the predictor variables used to make the interaction variables (e.g., ruminative brooding x SRET) were not correlated with each other.

\section{Effects of Mood Induction Tests}

To determine whether the mood induction was successful, participants' baseline scores (anger, sadness, happiness, and anxiety) were compared to their post-induction scores using ttests. Thus, if there was a significant difference between two VAS scores (e.g., happy at baseline and happy at post-mood induction), it was concluded that the mood induction was successful.

Negative mood inductions should result in an increase of anger, sadness, and anxiety, and a decrease of happiness, as seen in the SRET procedure used by Kuiper and Derry (1982). The analyses were significant for all four VAS measures at Time 1 (angry: $t=-5.12, p<.001$; happy: $t=7.57, p<.001$; sad: $t=-13.20, p<.001$; anxious: $t=3.21, p<.01$ ). It should be 
noted that the VAS scores for anxiety decreased significantly after the mood induction, which

2 was not expected. However, adolescents may have trouble differentiating between emotions,

3 particularly negative emotions such as anger and sadness (Williams, Connolly, \& Segal, 2001),

4 which may account for the unexpected result. The analyses were significant for three of the

5 VAS measures at Time 2 (angry: $t=-9.58, p<.001$; happy: $t=7.77, p<.001$; sad: $t=-38.72, p$

$6<.001)$. The VAS anxious scores were not significantly different before and after the mood

7 induction, although the relationship was approaching significance, suggesting that the mood

8 induction was still effective $(t=-1.78, p=.078)$. The VAS score descriptive statistics for both

9 time points are listed in Table A.2.

\section{Test of the Hypothetical Model}

The hypothesized model yielded acceptable goodness-of-fit indices, $\chi^{2}(23, N=92)=$

12 29.462, $p=.165, \chi^{2} / d f=1.281$, CFI (.967), RMSEA (.056). Thus, it was acceptable to further

13 analyze the model to test the hypotheses.

As predicted, the model showed a positive, significant pathway for the interaction of

15 the ruminative brooding subscale and the SRET variable at Time 1 on self-reported depressive

16 symptoms at Time $2(p<.05)$. The standardized coefficient for this relationship was .462,

17 which is considered a large effect (Kline, 2005). This coefficient indicates that the interaction

18 of brooding and SRET at Time 1 accounted for $21.34 \%$ of the variance in depressive

19 symptoms at Time 2. The interaction of ruminative reflection and negative self-referent

20 information processing was marginally significant in predicting a decrease in depressive

21 symptoms at Time $2(p=.089)$. This result goes beyond our hypothesis that negative self-

22 referent information processing and ruminative reflection would not predict increases in

23 depression by suggesting that there may be an inverse relationship. Interestingly, the main 
1 effects of brooding and the SRET variable at Time 1 did not have a significantly relationship

2 with depressive symptoms at Time 2. The model with its standardized cross-wave regression

3 weights is shown in Figure B.1.

4 A model-implied graph was constructed to examine the effect of the interaction

5 ruminative brooding and negative self-referent information processing on depressive

6 symptoms (Figure B.2). The graph demonstrates that the interaction effects of brooding and

7 negative self-referent information processing determine the level of depressive symptoms at

8 Time 2 much more than either construct alone. Additionally, the graph shows that an

9 adolescent's level of negative self-referent information processing increases, the effects of

10 ruminative brooding on depressive symptoms (six months later) is not as strong.

\section{Discussion}

This study tested the effects of the interaction of negative self-referent information

13 processing (i.e., a cognitive process) and ruminative response styles (i.e., cognitive styles) on

14 depressive symptoms in adolescents without a diagnosis of Major Depression at the beginning of

15 the study (Time 1). As noted by Ciesla and Roberts (2007), further understanding of the

16 combined effects of various negative cognitive styles and processes is necessary to understand

17 how these constructs interact to predict depressed mood. It has been established that negative

18 self-referent information processing is related to the onset and maintenance of depression (Derry

19 \& Kuiper, 1981; Dozois \& Dobson, 2001). It has also been established that rumination,

20 particularly the brooding subtype, is related to the onset and maintenance of depressive

21 symptoms (Burwell \& Shirk, 2007; Treynor et al., 2003). Additionally, research has shown that

22 ruminative reflection may lessen depressive symptoms over time (Burwell \& Shirk, 2007;

23 Saffrey \& Ehrenberg, 2007; Treynor et al., 2003). 
The hypothesized moderation model fit the data well. As expected, the interaction

2 of negative self-referent information processing and ruminative brooding predicted an

3 increase of depressive symptoms six months later. This finding is especially notable, as

4 this particular hypothesis had not been tested before. This result supports the idea that

5 negative cognitive styles (i.e., rumination) and negative cognitive processes (i.e., negative

6 self-referent information processing) can interact to predict depressive symptoms. Further,

7 additional examination of the combination of these constructs demonstrates that ruminative

8 brooding may be less impactful on depressive symptoms when an adolescent has high

9 levels of negative self-referent information processing. In other words, when an adolescent

10 is experiencing high levels of negative information processing and high levels of brooding,

11 clinicians may find it more effective to target their client's negative information processing

12 first to reduce depressive symptoms.

13 As expected, the interaction of ruminative reflection and negative self-referent

14 information processing did not interact to significantly predict an increase in depressive

15 symptoms. Despite this nonsignificant result, hypothesis 2 could not be confirmed, as the

16 level of nonsignificance obtained in the analysis did not meet the null hypothesis standards

17 which were established a priori. Thus, based on the data, it could not be concluded that the

18 combined effects of a negative cognitive process (i.e., negative self-referent information

19 processing) and a neutral or positive cognitive style (i.e., ruminative reflection) do not

20 predict depressive symptoms.

21 Nevertheless, the positive, significant relationship between the interaction of negative

22 self-referent information processing and ruminative brooding to depressive symptoms, as well as

23 the lack of relationship between the interaction of negative self-referent information processing 
1 and ruminative reflection to depressive symptoms, supports the idea that there is a difference in

2 how brooding and reflection contribute to the onset of depressive symptoms. This inference is

3 supported by the literature, which has shown that the correlation between reflection and

4 depression is often weaker than the correlation between brooding and depression (Burwell \&

5 Shirk, 2007; Ciesla \& Roberts, 2007; Treynor et al., 2003). Thus, it contributes to the growing

6 literature which seeks to combine Beck's cognitive theory and Nolen-Hoeksema's response

7 styles theory, and supports this combination in adolescent community-based populations (e.g.,

8 Alloy \& Abramson, 1999; Ciesla \& Roberts, 2002; Robinson \& Alloy, 2003).

9 This study should be considered within the context of its limitations. First, adolescent

10 depressive symptoms were measured solely with self-reports. Future studies may benefit from

11 using clinical interviews to measure depressive symptoms or clinical depression. Second,

12 depressed participants were excluded from analyses, which weakened the external validity of the

13 study. However, it is important to note that depressed participants were excluded to maintain

14 internal validity - the goal was to study the risk factors to depression. Thus, an inclusion of

15 participants who were currently depressed would have confounded depression risk factors with

16 symptoms of current depressive episodes. Third, participants were informed about the SRET

17 recall task at both time points. This was done to ensure that participants approached the task

18 with the same anticipations and expectations during both trials. If participants had not been

19 informed of the recall task when receiving instructions about the SRET at Time 1, they would

20 surely have anticipated the recall task at Time 2, and therefore would have a distinct advantage

21 during their second trial. While this did ensure consistency on the task, it is possible that the

22 participants performed better than they would have if they had not been informed about the

23 recall task, because they may have had more motivation to memorize the words in order to 
1 perform well on the task. Fourth, the sample in this study had disproportionately more male than

2 female participants. However, using gender as a covariate in the path model likely addressed

3 any influences this gender imbalance might have had on the results. Fifth, participants were

4 recruited from only one region of the country. It is possible that adolescents in this region may

5 differ from adolescents in the rest of Germany. Thus, generalizing these results to other regions

6 (or countries) should be done cautiously. Finally, because of the small sample size the statistical

7 power of the analyses performed is limited. Future studies would benefit from larger samples to

8 ensure more statistical power, which would lead to a more accurate understanding of the

9 constructs at hand.

10 Despite these limitations, this study has several strengths. The longitudinal design

11 allowed for the examination of predictive relationships. The longitudinal design is especially

12 helpful when analysing the relationship among these variables as research indicates both

13 schemata and response styles tend to be stable constructs over time. For example, Treynor et al.

14 (2003) found moderate test-retest reliability for brooding and reflection in an adult sample, and

15 the current study showed moderate correlations between brooding at time one and two $(r=.47)$

16 and reflection at time one and time two $(r=.48)$. Whether adolescent cognitive patterns are

17 stable remains unclear, however. Marcotte, L个vesque, and Fortin (2006) found that cognitive

18 distortions were state-dependent for girls and had mixed findings regarding distortions in male

19 adolescents. Future studies might consider testing different lengths of time when replicating this

20 longitudinal model to determine whether the stability of these traits is upheld for adolescent

21 samples. Furthermore, the investigation of the interaction of self-referent information processing

22 and ruminative response styles on adolescent depression has been largely untested until now. 
1 intervention settings. Based on current analyses, the interaction of negative self-referent

2 information processing and ruminative brooding may instigate or worsen depressive states.

3 Cognitive approaches to therapy may be especially beneficial for adolescents engaging in these

4 constructs. It is well established that cognitively oriented therapies can alleviate depressive

5 symptoms in adolescents (Compton et al., 2004). A clinical focus on the reduction of either or

6 both constructs could reduce long-term depressive symptoms. Additionally, these findings

7 could be applied to Mindfulness-Based Cognitive Therapy, which encourages clients to become

8 aware of their current thoughts so that they can detect negative thoughts earlier and stop

9 depression from occurring (Segal, Williams, \& Teasdale, 2002). An MCBT approach would

10 give adolescents at-risk for depression the opportunity to pay attention to their internal

11 mechanisms and monitor their negative information processing and ruminative tendencies.

12 Summarized, the current study confirmed a positive, statistically significant relationship

13 between the interaction of brooding and negative self-referent information processing on

14 depression six months later. Moreover, the interaction of reflection and negative self-referent

15 information processing does not have a positive relationship to depression six months later - it

16 may actually lessen these depressive symptoms. While studies with adult samples have

17 demonstrated this type of relationship between cognitive processes and styles (e.g., Ceisla \&

18 Roberts, 2007; Robinson \& Alloy, 2003), no study had previously confirmed its existence in

19 adolescent samples. Especially in light of this second interaction effect, it is necessary to

20 further investigate these constructs, especially in relation to the efficacy of cognitively-based

21 prevention and intervention programs for adolescents who are either at-risk for or are currently

22 experiencing depressive symptoms. 


\section{References}

Abela, J. R. Z., \& Hankin, B. L. (2011). Rumination as a vulnerability factor to depression during the transition from early to middle adolescence: A multiwave longitudinal study. Journal of Abnormal Psychology, 120(2), 259-271.

Ambramson, L. Y., Metalsky, G. I., \& Alloy, L. B. (1989). Hopelessness depression: A theorybased subtype of depression. Psychological Review, 96, 358-372.

Akaike, H. (1974). A new look at the statistical model identification. IEEE Transactions on Automatic Control, 19, 716-723.

Alloy, L. B., Abramson, L. Y., Murray, L. A., Whitehouse, W. G., \& Hogan, M. E. (1997). Self-referent information-processing in individuals at high and low cognitive risk for depression. Cognition and Emotion, 11, 539-568.

Alloy, L. B., \& Abramson, L. Y. (1999). The Temple-Wisconsin Cognitive Vulnerability to Depression (CVD) Project: Conceptual background, design, and methods. Journal of Cognitive Psychotherapy: An International Quarterly, 13, 227-262.

Alloy, L. B., Abramson, L. Y., Gibb, B. E., Crossfield, A. G., Pieracci, A. M., Spasojevic, J., \& Steinberg, J. A. (2004). Development antecedents of cognitive vulnerability to depression: Review of findings from the Cognitive Vulnerability to Depression project. Journal of Cognitive Psychotherapy, 18, 115-134.

American Psychiatric Association. (2000). Diagnostic and statistical manual of mental disorders ( $4^{\text {th }}$ ed., text revision $)$. Washington, D.C.

Beck, A. T. (1987). Cognitive models of depression. In R.L. Leahy, \& T.E. Dowd (Eds.), Clinical advances in cognitive psychotherapy: Theory and Application (pp. 29-61). New York: Spring Publishing Company. 
Beck, A. T. (1964). Thinking and depression II. Archives of General Psychiatry, 10, 561-571.

Beck, A. T. (1976). Cognitive therapy and the emotional disorders. New York, NY: International University Press.

Bentler, P. M. (1990). Comparative fit indexes in structural models. Psychological Bulletin, 107, $238-246$.

Bortz, J., \& Döring, N. (2002). Forschungsmethoden und Evaluation [Research methods and evaluation] ( $3^{\text {rd }}$ ed.). Berlin, Germany: Springer.

Burwell, R. A., \& Shirk, S. R. (2007). Subtypes of rumination in adolescence: Associations between brooding, reflection, depressive symptoms, and coping. Journal of Clinical Child and Adolescent Psychology, 36, 56-65.

Ciesla, J. A., \& Roberts, J. E. (2007). Rumination, negative cognition, and their interactive effects on depressed mood. Emotion, 7, $555-565$.

Compton, S.N., March, J.S., Brent, D., Albano, A.M., Weersing, V.R., \& Curry, J. (2004). Cognitive-behavioral psychotherapy for anxiety and depressive disorders in children and adolescents: An evidence-based medicine review. J. Am. Acad. Child Adolesc. Psychiatry, 43, 930-959.

Costello, J., Erkanli, E., \& Angold, A. (2006). Is there an epidemic of child or adolescent depression? Journal of Child Psychology and Psychiatry, 47, 1263-1271.

Derry, P. A., \& Kuiper, N. A. (1981). Schematic processing and self-reference in clinical depression. Journal of Abnormal Psychology, 90, 286-297.

Döpfner, M., Götz-Dorten, A., \& Lehmkuhl, G. (2008). Diagnostik-System für Psychische Störungen im Kindes- und Jugendalter nach ICD-10 und DSM-IV, DISYPS-II [Diagnostic system for mental disorders in children and adolescents based upon the 
ICD-10 and DSM-IV]. Bern, Switzerland: Huber.

Döpfner M., \& Lehmkuhl, G. (2000). DISYPS-KJ: Diagnostik-System für psychische Störungen im Kindes- und Jugendalter nach ICD-10 und DSM IV. Bern: Verlag Hans Huber.

Dozois, D. J. A., \& Dobson, K. S. (2001). Information processing and cognitive organization in unipolar depression: Specificity and comorbidity issues. Journal of Abnormal Psychology, 110, 236-246.

Dykman, B. M., Abramson, L. Y., Alloy, L. B., \& Hartlage, S. (1989). Processing of ambiguous and unambiguous feedback by depressed and nondepressed college students: Schematic biases and their implications for depressive realism. Journal of Personality and Social Psychology, 56, 431-445.

Gençöz, T., Voelz, Z.R., Gençöz, F., Petit, J.W., \& Joiner, T.E. Jr. (2001). Specificity of information processing styles to depressive symptoms in youth psychiatric inpatients. Journal of Abnormal Child Psychology, 29, 255-262.

Häufigkeit, Komorbidität und psychosoziale Beeinträchtigung von Depressiven Störungen bei Jugendlichen: Ergebnisse der Bremer Jugendstudie. [Frequency, comorbidity, and psychosocial impairment of depressive disorders in adolescents: results from the Bremer adolescent study.] Zeitschrift für Klinische Psychologie,

Psychiatrie und Psychotherapie, 46, 316-329.

Flynn, M., Kecmanovic, J., \& Alloy, L. B. (2010). An examination of integrated cognitive-interpersonal vulnerability to depression: The role of rumination, perceived social support, and interpersonal stress generation. Cognitive Therapy Research, 34, 456466. 
Garber, J., \& Hilsman, R. (1992). Cognitions, stress, and depression in children and adolescents. Child and Adolescent Psychiatric Clinics of North America, 1, 129167.

Gotlib, I. H., Kasch, K. L., Traill, S., Joormann, J., Arnow, B. A., \& Johnson, S. L. (2004). Coherence and Specificity of Information-Processing Biases in Depression and Social Phobia. Journal of Abnormal Psychology, 113, 386-398.

Hankin, B. L., \& Ambramson, L. Y. (2002). Measuring cognitive vulnerability to depression in adolescence: Reliability, validity and gender differences. Journal of Clinical Child and Adolescent Psychology, 31, 491-504.

Hilt, L. M., McLaughlin, K. A., \& Nolen-Hoeksema, S. (2010). Examination of the response styles theory in a community sample of young adolescents. Journal of Abnormal Child Psychology, 38, 545-556.

Hu, L., \& Bentler, P.M. (1999). Cutoff criteria for fit indexes in covariance structure analysis: Conventional criteria versus new alternatives. Structural Equation Modeling, 6, $1-55$.

Jacobs, R. H., Reinecke, M. A., Gollan, J. K., \& Kane, P. (2008). Empirical evidence of cognitive vulnerability for depression among children and adolescents: A cognitive science and developmental perspective. Clinical Psychology Review, 28, 759-782.

Joormann, J. (2004). Attentional bias in dysphoria: The role of inhibitory processes. Cognition and Emotion, 18, 125-147.

Jose, P. E., \& Brown, I. (2008). When does the gender difference in rumination begin? Gender and age differences in the use of rumination by adolescents. Journal of Youth and Adolescence, 37, 180-192. 
Kelvin, R. G., Goodyer, I. M., Teasdale, J. D., \& Brechin, D. (1999). Latent negative selfschema and high emotionality in well adolescents at risk for psychopathology. Journal of Child Psychology and Psychiatry, 40, 959-968.

Kline, R. B. (2005). Principals and practice of structural equation modeling ( $2^{\text {nd }}$ ed.). New York, NY: Guilford.

Kuiper, N. A., \& Derry, P. A. (1982). Depressed and nondepressed content self-reference in mild depressives. Journal of Personality, 50, 67-80.

Lewinsohn, P. M., Clarke, G., Hops, H., \& Andrews, J. (2008). Cognitive-behavioral treatment for depression adolescents. Behavior Therapy, 21, 385-401.

Lopez, C. M., Driscoll, K. A., \& Kistner, J. A. (2009). Sex differences and response styles: Subtypes of rumination and associations with depressive symptoms. Journal of Clinical Child \& Adolescent Psychology, 38, 23-75.

Lyubomirsky, S., \& Nolen-Hoeksema, S. (1993). Self-perpetuating properties of dysphoric rumination. Journal of Personality and Social Psychology, 65, 339 - 349.

Maes, H., Bohus, M., Lis, S., Krieger, S., Fünfgeld, M., Wark, H.-J., Baving, L., Olbrich, H., \& Berger, M. (1998). Untersuchung zur Stabilität kognitiver Schemata bei Depressiven nach affektiver Aufhellung durch Schlafentzug [Do negative self-ratings of depressives persist after affective improvement by sleep deprivation?]. Zeitschrift für Klinische Pyschologie, 27, 51-55.

Marcotte, D., L个vesque, N., Fortin, L. (2006). Variations of cognitive distortions and school performance in depressed and non-depressed high school adolescents: A two-year longitudinal study. Cognitive Therapy and Research, 30, 211-225.

Marttunen, M., Haarasilta, L., Aalto-Setälä, T., \& Pelkonen, M. (2003). Adolescent major 
depression: Course, comorbidity, and treatment. Psychiatria Fennica, 34, 33-49.

Miranda, J., \& Persons, J.B. (1988). Dysfunctional attitudes are mood-state dependent. Journal of Abnormal Psychology, 97, 76-79.

Moulds, M. L., Kandris, E., \& Williams, A. D. (2007). The impact of rumination on memory for self-referent material. Memory, 15, 814-821.

Needles, D. J., \& Ambramson, L. Y. (1992). Responses to depressed mood: Cognitive and affective consequences of rumination and distraction. Unpublished manuscript, University of Wisconsin-Madison.

Nolen-Hoeksema, S. (2001). Gender differences in depression. Current Directions in Psychological Science, 10, 173-176.

Nolen-Hoeksema, S., \& Jackson, B. (2001). Mediators of the sex difference in rumination. Psychology of Women Quarterly, 25, 37-47.

Nolen-Hoeksema, S., Larson, J., \& Grayson, C. (1999). Explaining the sex difference in depressive symptoms. Journal of Personality and Social Psychology, 77, 1061-1072.

Nolen-Hoeksema, S., \& Morrow, J. (1991). A prospective study of depression and posttraumatic stress symptoms after a natural disaster: the 1989 Loma Prieta earthquake. Journal of Personality and Social Psychology, 61, 115 - 121.

Nolen-Hoeksema, S., Parker, L. E., \& Larson, J. (1994). Ruminative coping with depressed mood following loss. Journal of Personality and Social Psychology, 67, 92-104.

Nolen-Hoeksema, S., Wisco, B. E., \& Lyubomirsky, S. (2008). Rethinking rumination. Perspectives on Psychological Science, 3, 400-424.

Prinstein, M.J., Chear, C.S.L., Guyer, A.E. (2005). Peer victimization, cue interpretation, and internalizing symptoms: Preliminary concurrent and longitudinal findings for children 
and adolescents. Journal of Clinical Child and Adolescent Psychology, 34, 11-24.

Pössel, P. (2011). Can Beck’s theory of depression and the Response Style Theory be integrated? Journal of Counseling Psychology, 58, 618-629.

Pössel, P., \& Knopf, K. (2008). An experimental test of the maintenance and vulnerability hypothesis of depression in consideration of the cognitive hierarchy. Depression and Anxiety, 25, E47-E55.

Pössel, P., Seemann, S., Ahrens, S., \& Hautzinger, M. (2006). Testing the causal mediation component of Dodge's social information processing model of social competence and depression. Journal of Youth and Adolescence, 35, 849 - 859.

Pössel, P., Seeman, S., \& Hautzinger, M. (2008). Impact of comorbidity in prevention of adolescent depressive symptoms. Journal of Counseling Psychology, 55(1), 106-117.

Robinson, M. S., \& Alloy, L. B. (2003). Negative cognitive styles and stress-reactive rumination interact to predict depression: A prospective study. Cognitive Therapy and Research, 27, 275-292.

Rutter, M. (2007). Psychopathological development across adolescence. Journal of Youth and Adolescence, 36, 101-110.

Saffrey, C., \& Ehrenberg, M. (2007). When thinking hurts: Attachment, rumination, and post relationship adjustment. Personal Relationships, 14, 351-368.

Schwartz, J. A. J., \& Koenig, L. J. (1996). Response styles and negative affect among adolescents. Cognitive Therapy and Research, 20, 13-36.

Segal, Z.V., Williams, J.M.G., \& Teasdale, J.D. (2002). Preventing depression: mindfulness-based cognitive therapy. New York: Guildford.

Shadish, W. R., Cook, T. D., \& Campbell, D. T. (2002). Experimental and quasi- 
experimental designs for generalized causal inference. Boston: Houghton Mifflin.

Steiger, J. H., \& Lind, J. M. (1980, May). Statistically based tests for the number of common factors. Paper presented at the Psychometrika Society meeting, Iowa City, Iowa.

Treynor, W., Gonzalez, R., \& Nolen-Hoeksema, S. (2003). Rumination reconsidered: A psychometric analysis. Cognitive Therapy and Research, 27, 247-259.

Ullman, J. B. (1996). Structural equation modeling. In B. Tabachnick \& L. Fidell (Eds.), Using multivariate statistics $\left(3^{\text {rd }}\right.$ ed., pp. 709 - 812). New York, NY: HarperCollins.

Whitmer, A., \& Gotlib, I.H. (2011). Brooding and reflection reconsidered: A factor analytic examination of rumination in currently depressed, formerly depressed, and never depressed individuals. Cognitive Therapy Research, 35, 99-107.

Williams, S., Connolly, J., \& Segal, Z. (2001). Intimacy in relationships and cognitive vulnerability to depression in adolescent girls. Cognitive Therapy and Research, 25, $477-$ 496.

Wilkinson, P.O., \& Goodyer, I.M. (2006). Attention difficulties and mood-related ruminative response style in adolescents with unipolar depression. Journal of Child Psychology and Psychiatry, 47, 1284-1291.

Wittchen, H. U. \& Perkonigg, A. (1997): DIA-X Fragebögen. In H. U. Wittchen \& H. Pfister (eds.). Instruktionsmanual zur Durchführung von DIA-X Interviews. Frankfurt: Swets Test Services, pp. 11-20. 
Table A.1

Descriptive Statistics and Intercorrelations among variables

\begin{tabular}{|c|c|c|c|c|c|c|c|c|}
\hline & 1 & 2 & 3 & 4 & 5 & 6 & 7 & 8 \\
\hline \multicolumn{9}{|l|}{$\overline{\text { SBB-DES }}$} \\
\hline 1 Time 1 & -- & & & & & & & \\
\hline 2 Time 2 & $.58 * *$ & -- & & & & & & \\
\hline \multicolumn{9}{|l|}{ RRS - R } \\
\hline 3 Time 1 & $.32 * *$ & $.23 *$ & -- & & & & & \\
\hline 4 Time 2 & .20 & .19 & $.48 * *$ & -- & & & & \\
\hline \multicolumn{9}{|l|}{ RRS - B } \\
\hline 5 Time 1 & $.24^{*}$ & .17 & $.67 * *$ & $.31 * *$ & -- & & & \\
\hline 6 Time 2 & $.24^{*}$ & $.26^{*}$ & $.49 * *$ & $.54 * *$ & $.47 * *$ & -- & & \\
\hline \multicolumn{9}{|l|}{ SRET } \\
\hline 7 Time 1 & .13 & .11 & .14 & -.07 & .15 & .07 & -- & \\
\hline 8 Time 2 & .03 & .10 & .05 & .16 & -.04 & -.14 & .16 & -- \\
\hline Mean & .70 & .69 & 1.93 & 1.87 & 2.07 & 2.08 & .16 & .21 \\
\hline Standard Deviation & .61 & .56 & .63 & .51 & .74 & .70 & .18 & .23 \\
\hline \multicolumn{9}{|c|}{$\overline{\text { Note. }} *^{*} p<.01 ; * p<.05 . \mathrm{SBB}-\mathrm{DES}=$ Self-Report questionnaire - Depression; $\mathrm{RRS}-\mathrm{R}=$} \\
\hline \multicolumn{9}{|c|}{ Ruminative Response Scale - Reflection subscale; RRS - B = Ruminative Response } \\
\hline Scale - Brooding sul & ale; SR & $\mathrm{ET}=\mathrm{S}$ & -refere & nt infor & mation $\mathrm{p}$ & rocessin & g task - & Negative \\
\hline
\end{tabular}


Table A.2

VAS Induction Scores - Descriptive Statistics

Mbaseline $\quad S D_{\text {baseline }} \quad M_{\text {post-induction }} \quad S D_{\text {post- }}$

Time 1

Angry

9.39

16.11

26.67

35.26

Happy

83.38

33.82

46.70

37.37

Sad

11.47

23.92

70.78

44.98

Anxious

32.73

31.19

20.48

29.41

Time 2

Angry

9.70

18.26

26.96

37.12

Нарpy

83.26

34.87

53.60

35.35

Sad

11.13

24.13

58.95

43.02

Anxious

11.89

20.93

17.00

28.43 


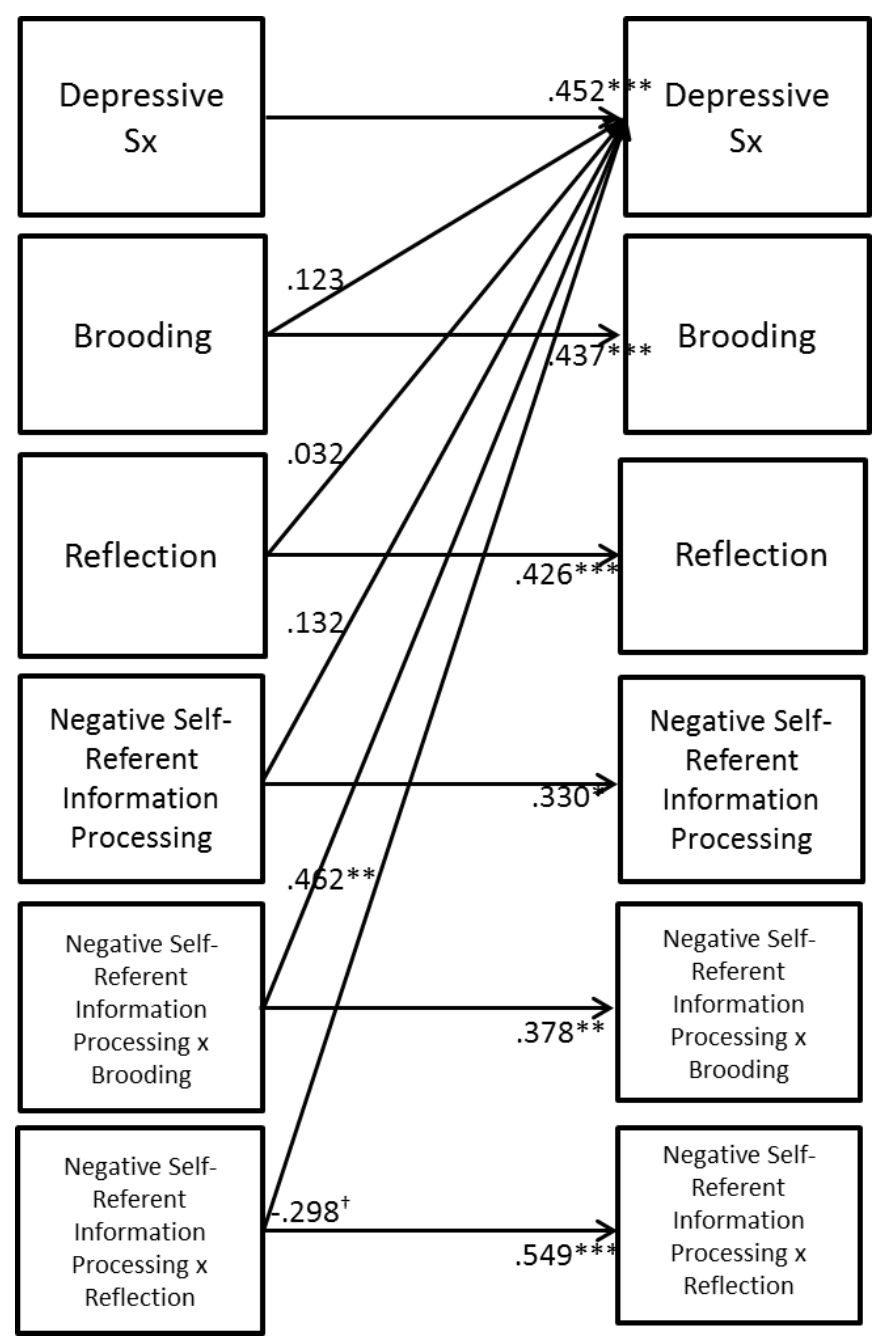

Figure B.1. Pathway Model of the Data. For the sake of comprehension and simplicity, only pathways related to the study's hypotheses are shown here. Depressive $\mathrm{Sx}=$ SelfReport Questionnaire - Depression; Reflection = Ruminative Responses Scale Reflection subscale; Brooding $=$ Ruminative Responses Scale - Brooding subscale; Negative Self-Referent Information Processing = Self-referent information processing task (SRET). *** $p<.001, * * p<.01, * p<.05, \dagger p<.10$. The variables in the path model were correlated through their residuals (i.e., error terms; all variables had an error term), based upon whether the variables were shown to correlate significantly in Table A. 1 . 


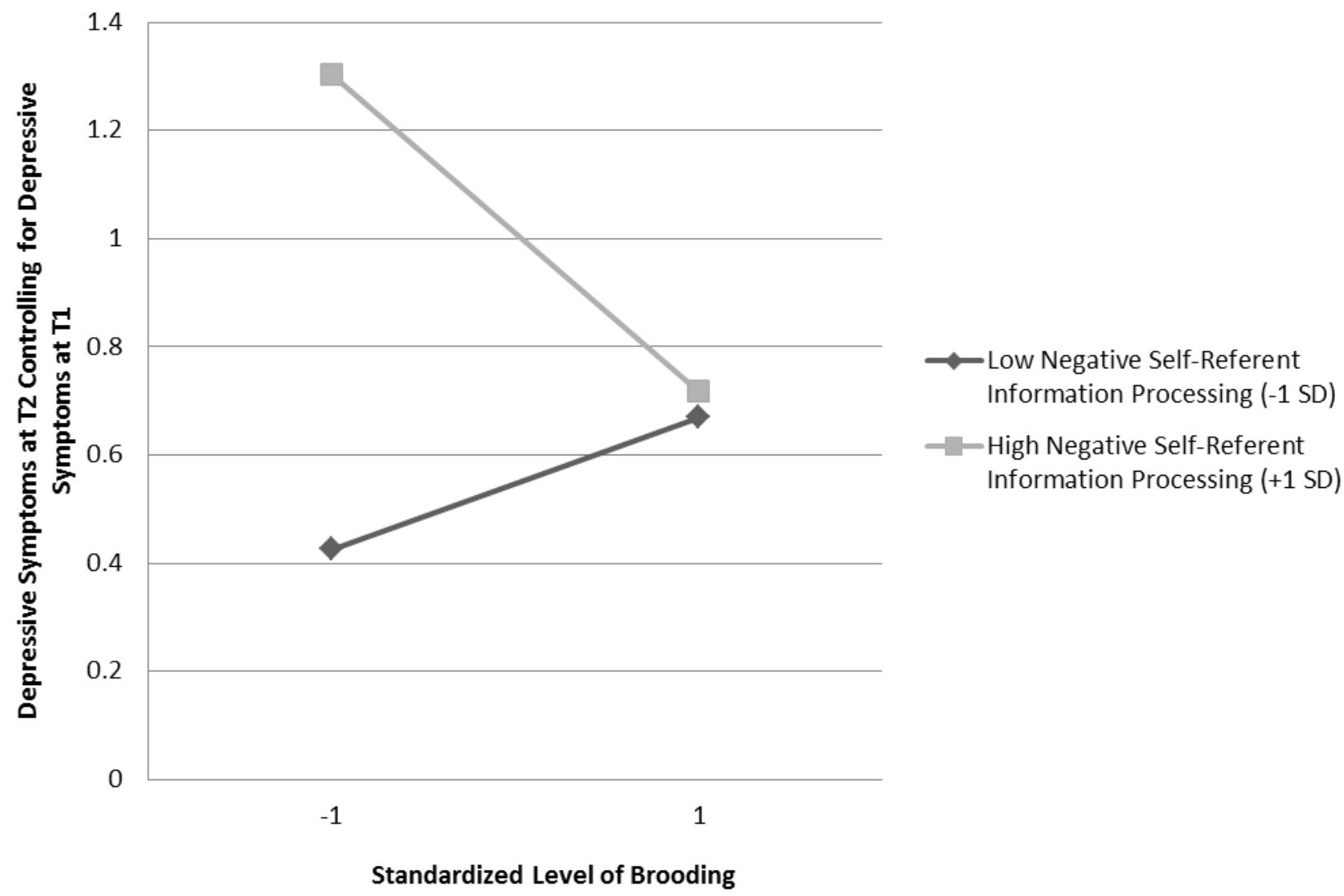

Figure B.2. Model Implied Graph of the Standardized Interaction Effect. For the sake of comprehension and simplicity, the model-implied plot points were calculated with standard deviations of -1 and 1 on both standardized negative self-referent information processing and standardized brooding scores. 